$3-2020$

\title{
A descriptive study of double burden of malnutrition in mothers of children with severe acute malnutrition admitted in children hospital and institute of child health, Multan
}

\author{
Saadia Khan \\ Children Hospital and Institute of Child Health, Multan, Pakistan \\ Umme Ammara \\ Children Hospital and Institute of Child Health, Multan, Pakistan \\ Reema Arshad \\ Aga Khan University, reema.arshad@aku.edu \\ Farah Naz \\ Children Hospital and Institute of Child Health, Multan, Pakistan \\ Kamran Ishfaq \\ Bahauddin Zakarya University, Multan, Pakistan
}

Follow this and additional works at: https://ecommons.aku.edu/

pakistan_fhs_mc_women_childhealth_paediatr

Part of the Maternal and Child Health Commons, and the Pediatrics Commons

\section{Recommended Citation}

Khan, S., Ammara, U., Arshad, R., Naz, F., Ishfaq, K. (2020). A descriptive study of double burden of malnutrition in mothers of children with severe acute malnutrition admitted in children hospital and institute of child health, Multan. JPMA. The Journal of the Pakistan Medical Association, 70(3), 417-420. Available at: https://ecommons.aku.edu/pakistan_fhs_mc_women_childhealth_paediatr/822 
RESEARCH ARTICLE

\title{
A descriptive study of double burden of malnutrition in mothers of children with severe acute malnutrition admitted in Children Hospital and Institute of Child Health, Multan
}

Saadia Khan1, Umme Ammara², Reema Arshad³, Farah Naz ${ }^{4}, K^{2}$ mran Ishfaq ${ }^{5}$

\begin{abstract}
Objective: To assess the nutritional status of mothers of severely malnourished children, and to evaluate the factors associated with inadequate caloric intake of children with severe acute malnutrition versus sufficient caloric intake by mothers.

Methods: The cross-sectional descriptive study was conducted from January to June 2016 at Children Hospital and Institute of Child Health, Multan, Pakistan, and comprised mothers of severely malnourished children admitted for treatment. Data was collected using a questionnaire administered through interviews. Elements noted included body mass index, 24-hour recall, dietary restriction during pregnancy, lactation and complimentary feeding patterns of the children. The mothers were also examined for clinical signs of iron deficiency anaemia.

Results: Of the 100 women, 20(20\%) were malnourished, 42(42\%) were of normal weight, and 38(38\%) were either overweight, pre-obese or obese. The caloric intake of $26(26 \%)$ mothers was less than $1500 \mathrm{kcal}$ per day, while 42(42\%) were taking between 2000-2500 kcal per day and 32(32\%) were taking $>2500 \mathrm{kcal}$ daily. Also, 67(67\%) women were suffering from anaemia and 80(80\%) women had some myths related with dietary restrictions during pregnancy, lactation and complimentary feeding of children. Overall, 23(23\%) women breastfed their babies.
\end{abstract}

Keywords: SAM, Severe acute malnutrition, Double burden, Obesity, BMI. (JPMA 70: 417; 2020). https://doi.org/10.5455/JPMA.290318

\section{Introduction}

There is a recent emergence of 'double burden of malnutrition', which consists of under-nutrition among children and over-nutrition in adults, especially women. This alarming shift from under-nutrition in childhood to over-nutrition in adulthood is the result of speedy economic development, globalisation, urbanisation, lifestyle changes, high-calory diets and reduced physical activity. Thus, over-nutrition and under-nutrition simultaneously occur among different age groups within the same population. ${ }^{1}$ This double burden of malnutrition has been noticed at country, household, and even individual levels. The more pronounced and visible pattern is an overweight or obese mother with a malnourished and underweight child. Although poverty is linked with under-nutrition among children, it can also cause obesity among adults. Moreover, under-nutrition

1,2,4Children Hospital and Institute of Child Health, Multan, Pakistan; ${ }^{3}$ Aga Khan University, Karachi, Pakistan; ${ }^{5}$ Bahauddin Zakarya University, Multan, Pakistan. Correspondence: Reema Arshad. e-mail: reemaarshad0@gmail.com in childhood also escalates the possibility of obesity in adulthood if the environmental factors are obesogenic. Both under-nutrition and over-nutrition has the potential to lead to chronic diseases. ${ }^{2}$ Low socioeconomic status (SES) and poverty contribute to the double burden of malnutrition. ${ }^{3}$

Obesity is a dangerous factor for many chronic diseases, such as respiratory illnesses, osteoporosis, diabetes mellitus (DM), hypertension (HTN), and cardiovascular diseases.4,5 Obesity is also a risk factor for the top four preventable diseases related to child mortality which are acute respiratory diseases, diarrhoea, neonatal sepsis and malaria. ${ }^{6}$ Almost $35 \%$ of child mortality is linked to macro- and -nutrient deficiencies. ${ }^{7}$ In addition to its effect on mortality, under-nutrition also affects human development in many aspects. The World Bank (WB) estimates that the annual cost burden of malnutrition to the global economy is approximately $\$ 80$ billion. 8 Similarly, obesity also drastically affects health and it is an independent factor for diseases like cardiovascular 
diseases, HTN, type 2 diabetes mellitus (T2DM), hyperlipidaemia, osteoarthritis, and a few types of cancer. 9,10

There are is a rapid rise in obesity in adult female general population of Pakistan and yet wasting in children is still rampant. According to the National Nutritional Survey 2011, Pakistan is also facing double burden of malnutrition. Female obesity is on the rise and on the other hand $24 \%$ children are severely stunted. ${ }^{11}$ On the one hand, the average female is consuming more calories than required while on the other, they are still facing significant micro-nutrient deficiencies such as iron, calcium and vitamin S A and D. Almost half of the adult women population is anaemic. ${ }^{12}$ The obese female population indicates the availability of sufficient food and caloric resources, but malnourished children indicate lack of food given to children or wrong feeding practices. It is an indication that although there are sufficient food sources present at home to meet energy requirements of the mothers, but the children are being underfed. These underfed children may be due to dietary restrictions and myths related to complementary feeding despite having enough food at home.

The current study was planned to assess the nutritional status of the mothers of severely malnourished children, and to evaluate the factors associated with inadequate caloric intake of children with severe acute malnutrition (SAM) versus sufficient caloric intake by the mothers.

\section{Subjects and Methods}

The cross-sectional descriptive study was conducted from January to June 2016 at Children Hospital and Institute of Child Health, Multan, Pakistan, and comprised mothers of severely malnourished children admitted for treatment. Non purposive simple selection technique was used to raise the sample. All the mothers of patients admitted during the study period who furnished consent were included. The mothers of children with other causes of malnutrition, like coeliac disease and chronic illnesses, and those who refused to give consent were excluded. Body mass index (BMI) was used to assess the nutritional status of the mothers and they were classified using the World Health Organisation (WHO) classification of BMI for South Asian populations. ${ }^{13}$

A questionnaire was designed and data was collected through detailed interviews with the mothers (Annexure). A pre-designed questionnaire was used to evaluate
Annexure: Questionnaire used for data collection.

\begin{tabular}{|c|c|c|}
\hline Name: & Age: & Contact no. \\
\hline Education: & Income level: & Address: \\
\hline Height: & Weight: & BMI: \\
\hline $\begin{array}{l}\text { Clinical signs for iron deficiency } \\
\text { Eye examination } \\
\text { Palm pallor } \\
\text { Tongue examination }\end{array}$ & & \\
\hline
\end{tabular}

\begin{tabular}{|l|l|l|l|}
\hline 24 Hour Recall \\
\hline Meal & Food item & Quantity & Kcal \\
\hline Breakfast & & & \\
Snack 1 & & & \\
Lunch & & & \\
Snack2 & & & \\
Dinner & & & \\
\hline
\end{tabular}

IIIness of child during past 6 months

\begin{tabular}{|l|c|c|c|c|}
\hline Disease & No & Once & Twice & $>\mathbf{3}$ \\
\hline $\begin{array}{l}\text { Pneumonia } \\
\text { Diarrhoea }\end{array}$ & & & & \\
\hline
\end{tabular}

Baby feed

\begin{tabular}{|l|c|c|c|}
\hline Breastfeeding & Yes & \multicolumn{2}{|c|}{ No } \\
\hline Complimentary feeding & Food item & Quantity & Frequency \\
\hline & & & \\
\hline Foods avoided & Food item & \multicolumn{2}{|c|}{ Reasons to avoid } \\
\hline $\begin{array}{l}\text { During pregnancy } \\
\text { During lactation }\end{array}$ & & \multicolumn{2}{|l}{} \\
\hline
\end{tabular}

dietary restriction during pregnancy, lactation, breastfeeding and complimentary feeding patterns of children. A 24-hour dietary recall was also taken to evaluate the daily caloric intake of the subjects. The mothers were asked to recall every single item they had eaten in the preceding 24 hours. The quantity of food was calculated by showing the mothers standard cups and spoons. The 24-hour recall was evaluated using Pakistan Food Composition Tables. 14 As the mothers were not literate. It was not possible to obtain a 3-day written recall for dietary evaluation.

Mothers were also examined for clinical signs of iron deficiency anaemia i.e., palm paleness, eye and tongue examination. Risk factors associated with SAM children were further evaluated in percentages according to underweight and overweight women.

\section{Results}

Of the 100 women, $20(20 \%)$ were malnourished, $42(42 \%)$ were of normal weight, $17(17 \%)$ were overweight, $14(14 \%)$ were pre-obese and $7(7 \%)$ were obese. The overall mean age was $25.7 \pm 3.4$ years. The caloric intake 
Table: Risk factors leading to SAM in children with underweight and overweight/obese mothers.

\begin{tabular}{|c|c|c|c|}
\hline $\begin{array}{l}\text { Risk factors leading to } \\
\text { SAM in children }\end{array}$ & $n$ & $\begin{array}{c}\text { SAM children of } \\
\text { underweight mothers }\end{array}$ & $\begin{array}{l}\text { SAM children of } \\
\text { overweight and } \\
\text { obese mothers }\end{array}$ \\
\hline Lack of breastfeeding & 77 & $32(32 \%)$ & $45(45 \%)$ \\
\hline $\begin{array}{l}\text { Lack of adequate } \\
\text { complimentary feeding }\end{array}$ & 68 & $28(28 \%)$ & $40(40 \%)$ \\
\hline $\begin{array}{l}\text { Food restrictions due } \\
\text { to myths/taboos }\end{array}$ & 33 & $33(33 \%)$ & $47(47 \%)$ \\
\hline $\begin{array}{l}\text { Frequent infections } \\
\text { i.e. Diarrhoea }\end{array}$ & 16 & $16(16 \%)$ & $24(24 \%)$ \\
\hline Pneumonia & 30 & $12.2(12.2 \%)$ & $17.7(17.7 \%)$ \\
\hline
\end{tabular}

"Severe acute malnutrition (SAM) is defined by a very low weight for height (below -3z scores of the median World Health Organisation [WHO] growth standards), by visible severe wasting, or by the presence of nutritional oedema.". 24

of $26(26 \%)$ mothers was less than $1500 \mathrm{kcal}$ per day, while $42(42 \%)$ were taking between $2000-2500 \mathrm{kcal}$ per day and $32(32 \%)$ were taking $>2500 \mathrm{kcal}$ daily. Also, $67(67 \%)$ women were suffering from anaemia and $80(80 \%)$ women had some myths related with dietary restrictions during pregnancy, lactation and complimentary feeding of children (Table). Overall, 23(23\%) women breastfed their babies.

Despite the availability of adequate diet at home, all children were suffering from SAM although 29(29\%) of the women were overweight and obese.

\section{Discussion}

Pakistan is a developing country facing a double burden' of malnutrition. The current findings that $29 \%$ mothers of SAM children were themselves overweight or obese is indicative of the double burden of malnutrition which leads to disorders linked with under-development, poor quality of life because of infectious diseases and nutrition deficiencies, and preventable diseases secondary to urbanisation or rapid industrialisation. ${ }^{2}$

In Pakistan, adult obesity and overweight has become a public health hazard in the last two decades. A study in Thailand has also shown similar results regarding alarming magnitudes of overweight and obesity in urban populations where females tend to have higher proportion of overweight and obesity than males of similar population. ${ }^{14}$ Researches from Bangladesh and Indonesia have observed low physical activity and highcalorie diets mainly composed of junk foods and less consumptions of fruits and vegetables further contribute to obesity. ${ }^{15,16}$ Studies in Pakistan also found results similar to this study. 5,17
In a study conducted in several low-income countries, a growing problem of under-nutrition and over-nutrition was also found, like in Pakistan. The children are dying because malnutrition and being underfed, and the adults, especially women, are becoming more overweight and facing complications related to obesity. ${ }^{18} \mathrm{~A}$ research in Brazil slums also showed this contradictory co-occurrence of under-nutrition and over-nutrition in the same family. ${ }^{19}$

According to a study, pregnancy and early childhood is a crucial time to provide a good base for adequate growth and development. The poor nutritional status in children under the age of five specifies the nutritional status and dietary intake of mothers during pregnancy and complimentary feeding after 6 months. The trend of obese mothers and SAM children indicates that although there is sufficient availability of food resources at home, the children are still not fed enough calories to provide adequate growth and development. The insufficient calorie intake of children is mainly due to lack of breastfeeding and intake of diluted formula via bottle. 20 Similar trends were reported by this study.

Related findings were observed in a report by the United Nations International Children's Emergency Fund (UNICEF) that children's diet is also lacking in vital nutrients due to certain myths and taboos regarding food intake during pregnancy, lactation and complementary food. Nutritious foods like meat, eggs, nuts and seeds are prohibited to pregnant and lactating women because of myths of miscarriage and complications associated with these foods. The children are often given commercially prepared expensive formulas and cereals in diluted forms because their concentrated forms are believed to cause diarrhoea. Due to these food myths and taboos, the child's diet is deficient in calories and vital nutrients. 21,22 According to studies, there is also an increase in the threat of overweight and obesity among children despite the persistently high burden of under-nutrition. Over nutrition phenomenon is age-related and related to the simultaneous decrease in physical activity. The strategies must have interventions for the prevention of obesity among children by promoting physical activity and healthy dietary intake, especially in schools. 23,24 Another study also stated that it is fundamental to recognise that both infant / child malnutrition and maternal obesity may have a common aetiology, both of which are significantly associated with poverty and 


\section{adverse conditions of their environment.25,26}

There is a threat of emerging burden of malnutrition in Pakistan. Further studies are recommended to find out the reasons for inadequate calorie intake in children whose mothers are either of normal weight, overweight or obese.

\section{Conclusion}

Only about one-fourth of the women were undernourished and most of them were consuming adequate calories or more than what was required for them. On the other hand, their children were severely malnourished. The breastfeeding rates were also low and diluted bottle feeding and insufficient complementary feeding was common. There were many myths and taboos associated with dietary intake during pregnancy, lactation and complimentary feeding of children.

\section{Disclaimer: None. \\ Conflict of Interest: None. \\ Source of Funding: None.}

\section{References}

1. Kolcic I. Double burden of malnutrition: A silent driver of double burden of disease in low-and middle-income countries. J Glob Health 2012; 2: 020303.

2. Ravishankar A. Is India shouldering a double burden of malnutrition? J Health Manag 2012; 14: 313-28.

3. Delisle $\mathrm{H}$, Batal $\mathrm{M}$. The double burden of malnutrition associated with poverty. Lancet 2016; 387: 2504-5.

4. Must A, Spadano J, Coakley EH, Field AE, Colditz G, Dietz WH. The disease burden associated with overweight and obesity. JAMA 1999; 282: $1523-9$

5. Burton BT, Foster WR, Hirsch J, Van Itallie TB. Health implications of obesity: an NIH Consensus Development Conference. Int J Obes 1985; 9: 155-70.

6. World Health Organization. World malaria report 2009. Geneva, Switzerland: WHO Press, 2009.

7. Black RE, Allen LH, Bhutta ZA, Caulfield LE, De Onis M, Ezzati M, et al. Maternal and child undernutrition: global and regional exposures and health consequences. Lancet 2008; 371: 243-60.

8. Subramanian SV, Kawachi I, Smith GD. Income inequality and the double burden of under-and overnutrition in India. J Epidemiol Community Health 2007; 61: 802-9.

9. Swinburn BA, Sacks G, Hall KD, McPherson K, Finegood DT, Moodie $\mathrm{ML}$, et al. The global obesity pandemic: shaped by global drivers and local environments. Lancet $2011 ; 378$ : 804-14.

10. Campos P, Saguy A, Ernsberger P, Oliver E, Gaesser G. The epidemiology of overweight and obesity: public health crisis or moral panic? Int J Epidemiol 2006; 35: 55-60.

11. Di Cesare M, Bhatti Z, Soofi SB, Fortunato L, Ezzati M, Bhutta ZA Geographical and socioeconomic inequalities in women and children's nutritional status in Pakistan in 2011: an analysis of data from a nationally representative survey. Lancet Glob Health 2015; 3: e229-39.

12. Butchart SH, Walpole M, Collen B, Van Strien A, Scharlemann JP, Almond RE, et al. Global biodiversity: indicators of recent declines. Science 2010; 328: 1164-8.

13. WHO EC. Appropriate body-mass index for Asian populations and its implications for policy and intervention strategies. Lancet 2004; 363: 157-63.

14. UNICEF. Food Composition Table for Pakistan (revised 2001). Islamabad, Pakistan. [Online] 2001 [Cited 2014 September 02]. Available from URL: http://www.fao.org/fileadmin/templates/ food_composition/documents/regional/Book_Food_Composition _Table_for_Pakistan_.pdf

15. Aekplakorn W, Kosulwat V, Suriyawongpaisal P. Obesity indices and cardiovascular risk factors in Thai adults. Int J Obes (Lond). 2006; 30: 1782-90.

16. Boutayeb A, Boutayeb S. The burden of non communicable diseases in developing countries. Int J Equity Health 2005; 4: 2.

17. Oddo VM, Rah JH, Semba RD, Sun K, Akhter N, Sari M, et al. Predictors of maternal and child double burden of malnutrition in rural Indonesia and Bangladesh. Am J Clin Nutr 2012; 95: 951-8.

18. Bhutta ZA, Hafeez A, Rizvi A, Ali N, Khan A, Ahmad F, et al. Reproductive, maternal, newborn, and child health in Pakistan: challenges and opportunities. Lancet 2013; 381: 2207-18.

19. Black RE, Victora CG, Walker SP, Bhutta ZA, Christian P, de Onis M, et al. Maternal and child undernutrition and overweight in low-income and middle-income countries. Lancet 2013; 382: 427-51.

20. Silveira KB, Alves JF, Ferreira HS, Sawaya AL, Florêncio TM. Association between malnutrition in children living in favelas, maternal nutritional status, and environmental factors. J Pediatr (Rio J) 2010; 86: 215-20.

21. Khan S, Iqbal I, Arshad R, Ishfaq K. Breast feeding; awareness and complementary feeding in mothers of children with severe acute malnutrition at nutrition stabilization centre children hospital and institute of child health Multan. Professional Med J 2015; 22: 1531 34.

22. UNICEF. Tracking progress on child and maternal nutrition: a survival and development priority. New York, USA: UNICEF, 2009.

23. Vitolo MR, Gama CM, Bortolini GA, Campagnolo PD, Drachler Mde L. Some risk factors associated with overweight, stunting and wasting among children under 5 years old. J Pediatr (Rio J) 2008; 84: 251-7.

24. Jafar T, Qadri Z, Islam M, Hatcher J, Bhutta ZA, Chaturvedi N. Rise in childhood obesity with persistently high rates of undernutrition among urban school-aged Indo-Asian children. Arch Dis Child 2008; 93: 373-8.

25. Collaboration APCS. The burden of overweight and obesity in the Asia-Pacific region. Obes Rev 2007; 8: 191-6.

26. Abrahams Z, Mchiza Z, Steyn NP. Diet and mortality rates in SubSaharan Africa: stages in the nutrition transition. BMC Public Health 2011; 11: 801 . 